\title{
Article \\ In-Flight Demonstration of Stall Improvement Using a Plasma Actuator for a Small Unmanned Aerial Vehicle
}

\author{
Satoshi Sekimoto ${ }^{1, *,+} \mathbb{1}$, Hiroki Kato ${ }^{2}$, Kozo Fujii $^{1} \mathbb{1}$ and Hiroshi Yoneda ${ }^{3}$ \\ 1 Department of Information and Computer Technology, Faculty of Engineering, Tokyo University of Science, \\ Tokyo 125-8585, Japan; fujii@rs.tus.ac.jp \\ 2 Independent Researcher, Tochigi 320-0834, Japan; kato.hiroki.4381@gmail.com \\ 3 Department of Aerospace Engineering, Faculty of Science and Engineering, Teikyo University, \\ Utsunomiya 320-8551, Japan; yoneda@ase.teikyo-u.ac.jp \\ * Correspondence: satoshi-sekimoto@go.tuat.ac.jp \\ + Current address: Department of Mechanical Systems Engineering, Faculty of Engineering, Tokyo University \\ of Agriculture and Technology, Tokyo 184-8588, Japan.
}

check for updates

Citation: Sekimoto, S.; Kato, H.; Fujii, K.; Yoneda, H. In-Flight

Demonstration of Stall Improvement

Using a Plasma Actuator for a Small Unmanned Aerial Vehicle. Aerospace 2022, 9, 144. https://doi.org/ 10.3390 /aerospace 9030144

Academic Editor: Srikanth

Gururajan

Received: 17 November 2021

Accepted: 3 March 2022

Published: 7 March 2022

Publisher's Note: MDPI stays neutral with regard to jurisdictional claims in published maps and institutional affiliations.

Copyright: (c) 2022 by the authors Licensee MDPI, Basel, Switzerland. This article is an open access article distributed under the terms and conditions of the Creative Commons Attribution (CC BY) license (https:// creativecommons.org/licenses/by/ $4.0 /)$.

\begin{abstract}
The flow control capability (especially for separation control) of a dielectric-barrierdischarge plasma actuator (DBD-PA) has been investigated extensively. However, these studies have been conducted under ideal conditions, such as wind tunnels and computational environments, and limited studies have investigated the effects of plasma actuators in an actual environment. In this study, the flow control capability of a DBD-PA under natural and in-flight conditions was investigated via field flight tests using an unmanned aerial vehicle (UAV). The DBD-PA driving system was constructed with a small high-voltage power supply on a 2-m-span UAV. With the support of an autonomous flight system, the pitch angle gradually increased as the airspeed decreased, and the stall occurred from the cruise state. This flight procedure was conducted with the DBD-PA on or off, and 246 pairs of flights were operated. The results revealed that a flight state with a higher pitch angle and lower airspeed occurred when DBD-PA was switched on. In addition, the moment of stall was quantitatively determined from the flight log, and it was confirmed that the maximum pitch angle when DBD-PA was switched on tended to be larger than that when DBD-PA was switched off. These results indicate that flow control with a DBD-PA on a 2-m-span UAV was effective in natural and in-flight situations.
\end{abstract}

Keywords: plasma actuator; unmanned aerial vehicle; flight testing; stall delay; autonomous flight system; small high-voltage power supply

\section{Introduction}

Many compact flow control devices, including a dielectric-barrier-discharge plasma actuator (DBD-PA), have been developed [1,2]. As displayed in Figure 1, DBD-PA comprises two electrodes and a dielectric with a thickness of approximately several hundred $\mu \mathrm{m}$ to several millimeters. A DBD-PA is typically driven with alternating high voltage (HV). When an alternating HV is applied between the two electrodes, dielectric-barrier-discharge (DBD) plasma is generated, and ions around the plasma region are moved by an electric field, which results in a small flow of a few $\mathrm{m} / \mathrm{s}$ [3-6].

Benard et al. [7] extensively reviewed a DBD-PA and detailed typical single DBD-PA's voltage-current characteristics, plasma physics, and performance of flow induction. Furthermore, approaches for modifying the discharge behavior and increasing its performance were discussed. Flow control was achieved by integrating the induced flow with the target mainstream. The simplicity of DBD-PA allows its installation in locations where traditional flow control devices cannot be used. Furthermore, because flow induction is caused by electrical phenomena rather than mechanical movement, a DBD-PA does not have mechanical moving parts. Moreover, it exhibits excellent responsiveness. 


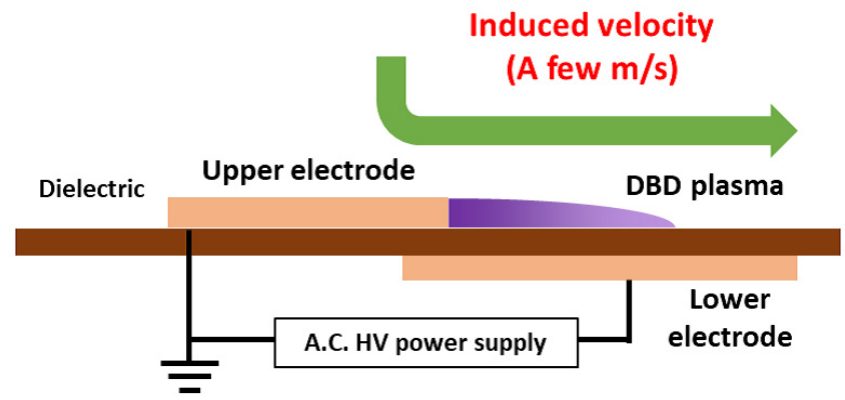

Figure 1. Schematic of a DBD-PA.

In early DBD-PA research, Post and Corke [8] demonstrated the flow control capability of a DBD-PA experimentally, and Visbal et al. [9] demonstrated the capability by using a computational method. Studies, including the previously mentioned two, have reported that a DBD-PA is effective for flow control at the Reynolds number less than the order of $10^{5}$ [10-12]. To improve the effectiveness of the flow control of a DBD-PA, actuator geometry (e.g., a DBD vortex generator [13], a triode PA [14]), and "burst-mode (also known as duty cycle or unsteady operation)" actuation have been investigated.

When a continuous alternating voltage was applied (hereinafter, normal mode), the DBD-PA induced a steady flow. Moreover, for an alternating voltage with on and off as displayed in Figure 2, a DBD-PA induced an unsteady flow. In Figure 2, the sinusoidal line plot corresponds to the alternating voltage with the base frequency $f_{\text {base }}$. The burst frequency $f^{+}$is defined as the inverse of the time of the duty cycle $T$. $T_{o n}$ is the time a DBD-PA is switched on.

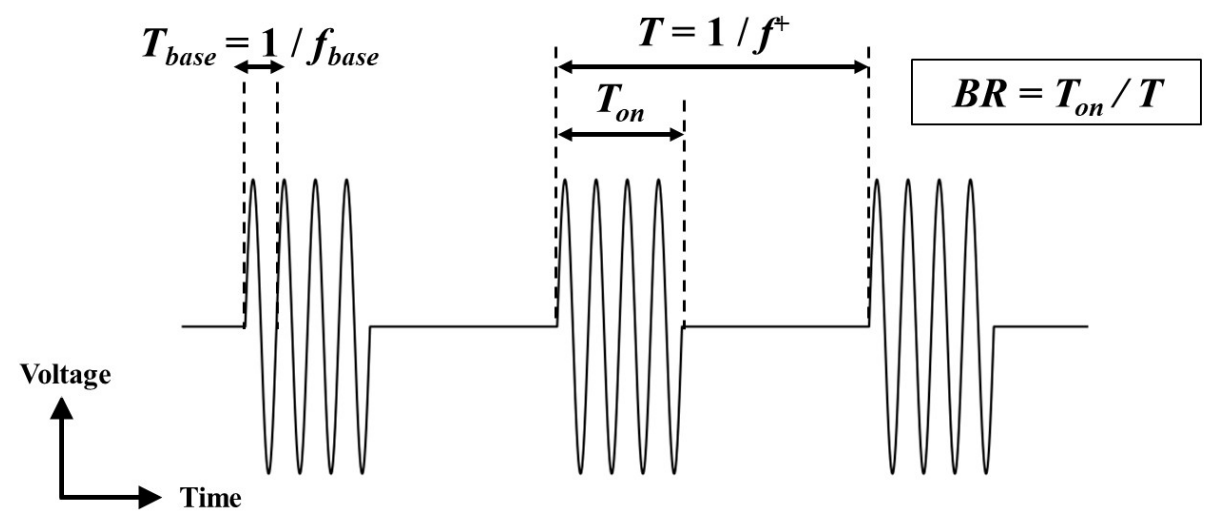

Figure 2. Schematic of the burst-mode driving. In this figure, the burst ratio $(B R)$ was set to $40 \%$.

The ratio $T_{o n} / T$ is called the burst ratio $B R$. The energy consumption in the burst mode was less than that in the normal mode because a DBD-PA was switched on during a limited period. Note that the energy consumption in the burst mode was considered to be proportional to the $B R$. Despite a lower energy consumption, previous studies have reported that burst-mode actuation is more effective than the normal-mode actuation for suppressing flow separation, especially under a low Reynolds number condition $[12,15,16]$.

Studies have discussed the appropriate burst-mode actuation for separation control around an airfoil, focusing on the nondimensional burst frequency $F^{+}$[15-19]. Our previous study concluded that a high nondimensional frequency (approximately 6) was appropriate for suppressing separation around the stall angle, where actuation with a nondimensional frequency of approximately 1 was effective under deep stall conditions [12]. $F^{+}$ is defined as follows:

$$
F^{+}=\frac{f^{+} c}{u_{\infty}}
$$


where $c$ is the chord length of the airfoil, and $u_{\infty}$ is the freestream velocity. Skourides et al. [20] applied nanosecond-pulse DBD-PA [21] on a NACA0015 airfoil under post-stall angle and a higher Reynolds number than this study and also concluded that $F^{+}=1$ and 2 were effective. Our former studies showed that the burst-mode actuation is particularly effective at angles of attack close to the stall angle (because the separated shear layer is closely located near the airfoil surface, and specific burst frequencies are effective for promoting transition) [11,12,16].

In addition, it was confirmed that burst-mode actuation can reduce the drag even at angles of attack lower than the stall angle when an appropriate burst frequency is used $[11,12,22]$. These are the reasons why we selected burst-mode actuation for this flight test. In addition to the burst frequency, Borghi et al. [23] devised the geometry of a DBD-PA to control the separated flow around the airfoil. Furthermore, they introduced a set of vectorized plasma jet actuator arrays that can induce perpendicular and tangential flows.

Zoppini et al. [24] installed a multi-chip DBD-PA on a airfoil model without an end plate and discussed its control performance in the stall range through particle image velocimetry (PIV) measurement. They reported that a DBD-PA worked around the span center, whereas it only induced a slight modification of the local streamlines, which revealed that a DBD-PA with a shorter span can achieve similar separation control.

We [25] performed wind tunnel experiments with a half-span wing model, assuming the main wing of an actual UAV. A DBD-PA was installed at the leading edge in the spanwise direction. The DBD-PA length was shortened from the wing tip side, and the control effects were compared. The results revealed that the overall control performance did not change even if the PA was marginally shortened because the influence of the wing tip vortex was strong near the wing tip.

Previous studies have provided novel knowledge for flow control using a DBD-PA. However, these insights have been acquired under ideal conditions, such as wind tunnels, and have been computationally investigated, and few studies have investigated the effects of PA in an actual environment. Focusing on the application to aircraft, an unmanned aerial vehicle (UAV) falls under the Reynolds number of $10^{5}$. UAVs are typically sensitive to unexpected internal or external uncertainties, rendering it difficult to fly autonomously in a dynamic natural environments.

Achieving high autonomy using model-based controllers requires the construction of accurate mathematical UAV models. However, predicting and modeling the dynamics of UAVs in advance is difficult. Furthermore, some difficulties exist in detecting the current state owing to sensor accuracy, error, and imperfection. Therefore, the construction of UAV control models [26] and automatic path planning [27] have been studied using reinforcement learning.

Developing an intelligent control system is a critical for improving flight performance and safety. As a novel approach, we proposed mounting a DBD-PA on the UAV as additional equipment for flight performance improvement. Installing a DBD-PA in the current system is easy. Furthermore, because it is very light and thin, it can work aerodynamically only when necessary.

As the power system of an aircraft is separated from the ground, it is necessary to mount an HV power supply system to drive the DBD-PA of the aircraft. There are examples of mounting a DBD-PA on a wind turbine [28] and a glider [29] of a size large enough for humans to ride; and in these examples, the power supply of the size used in wind-tunnel tests is mounted as is, to exploit the size of the equipment. As UAVs have limited loading weights and dimensions, it is difficult to establish a DBD-PA drive system for UAVs. Few studies have been conducted on UAV flight testing using DBD-PAs.

In studies in which DBD-PAs were mounted on UAVs [30,31], Minipuls was used [32]. The DBD-PA drive system can be mounted on UAVs using this small HV power supply, and flight tests with a DBD-PA mounted UAV have been conducted. However, these studies are limited to the initial examination of UAV performance improvement by DBD-PAs, and a detailed discussion has not yet been conducted. 
Our final objective is to improve the feasibility of DBD-PA, which thus far has been effective only in wind tunnel tests, to a practical level for UAV performance improvement. In this study, field flight tests are conducted, and the flow control capability of a DBD-PA under natural and in-flight conditions is investigated. To confirm the feasibility of the flow control capability of DBD-PA, we introduce a generally available hobby-use UAV and an autonomous flight system, rather than using a customized UAV in this flight experiment. Initial test data obtained in this study was reported in Ref. [33] where a limited and preliminary data analysis was made. The present study makes a detailed analysis of all the flight data obtained in a series of flight tests and identifies the flow control authority of DBD-PA under atmospheric conditions.

\section{Experimental Equipment}

\subsection{UAV}

The following items were considered when selecting a UAV for use in our flight test.

- $\quad$ Scale and speed:

The Reynolds number based on the wing chord length and flight speed should be approximately $1.0 \times 10^{5}$.

- $\quad$ Loading weight and space:

A small HV power supply (see Section 2.2), a battery, and an autonomous flight control module (see Section 2.3) can be mounted.

- Availability and ease of assembly:

Assuming that the UAV could crash and be totally lost, components should be cheap and easy to purchase as well as easy to construct.

Based on these requirements, "Voltantex RC Ranger EX [34]" (Figure 3) was selected; its specifications are listed in Table 1. This UAV has a main wing with the chordwise section of the Clark-Y-like geometry. The main wing shape can be seen in a side-view schematic shown in Ref. [34]. Actual measurement showed that the maximum thickness of this wing was $12.5 \%$ of the chord. The aerodynamic properties of the present UAV can be found in Ref. [35], where Hamada et al. conducted flight test experiments on this UAV and investigated the aeroelastic flutter.

As described in Section 2.2, we caused UAV stall from the cruise state. However, the original elevator area surface was insufficient for generating a pitching moment near the stall. Therefore, the elevator was expanded with a balsa to increase the pitch-control power near the stall angle. The airspeed was measured with a pitot tube at the nose. A lithium polymer battery (Hyperion G5 SV 25-50C $4000 \mathrm{mAh} 4 \mathrm{~S}$ ) was installed to drive the UAV. In Figure 3, the brown tapes at the leading edge of both main wings were DBD-PAs.

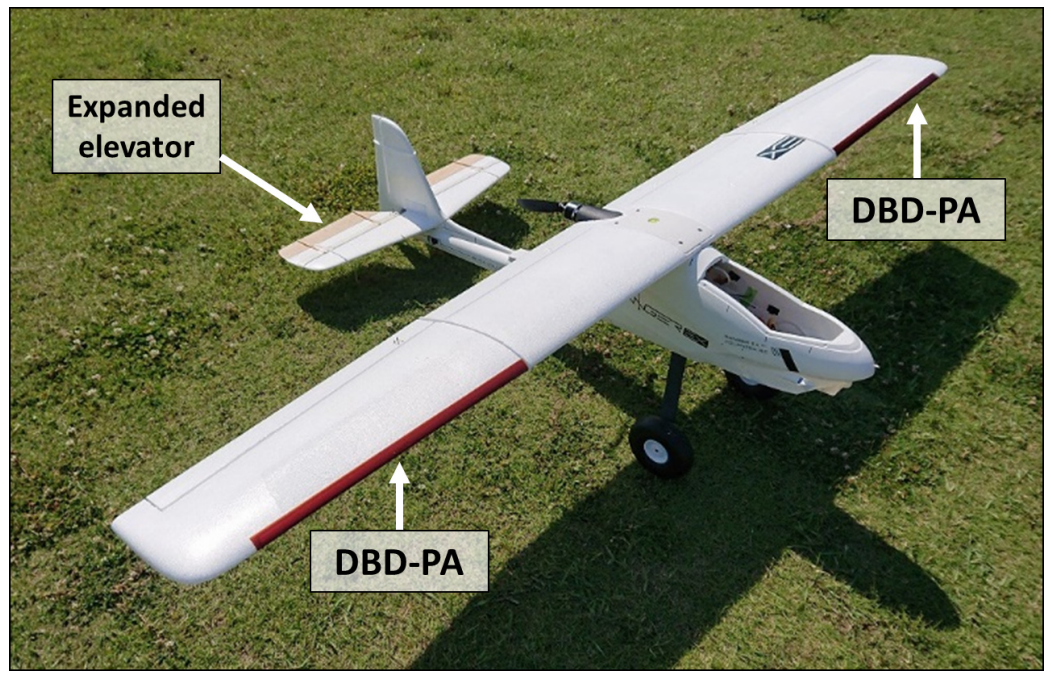

Figure 3. Voltantex RC Ranger EX. Plasma actuators were attached to both main wings; notably, the front cover is removed in this picture. 
Table 1. Specifications of the UAV.

\begin{tabular}{ll}
\hline Wing span & $1980 \mathrm{~mm}$ \\
\hline Overall Length & $1170 \mathrm{~mm}$ \\
\hline Mean aerodynamic chord & $216 \mathrm{~mm}$ \\
\hline Wing surface & $0.426 \mathrm{~m}^{2}$ \\
\hline
\end{tabular}

\subsection{Small HV Power Supply and PA}

A small HV power supply (Figure 4) was mounted on the UAV to drive the DBD-PAs. This small HV power supply was developed by Masuda Research, Inc. The specifications are illustrated in Table 2. The features of this power supply were previously published by the authors' group in Ref. [36]. This section summarizes the features of this power supply for application on a UAV. This power supply was designed to drive a PA with a total length of $1000 \mathrm{~mm}$ installed on the main wing, and the design load in the table was set based on the capacitance of the DBD-PA under the nonoperated condition.

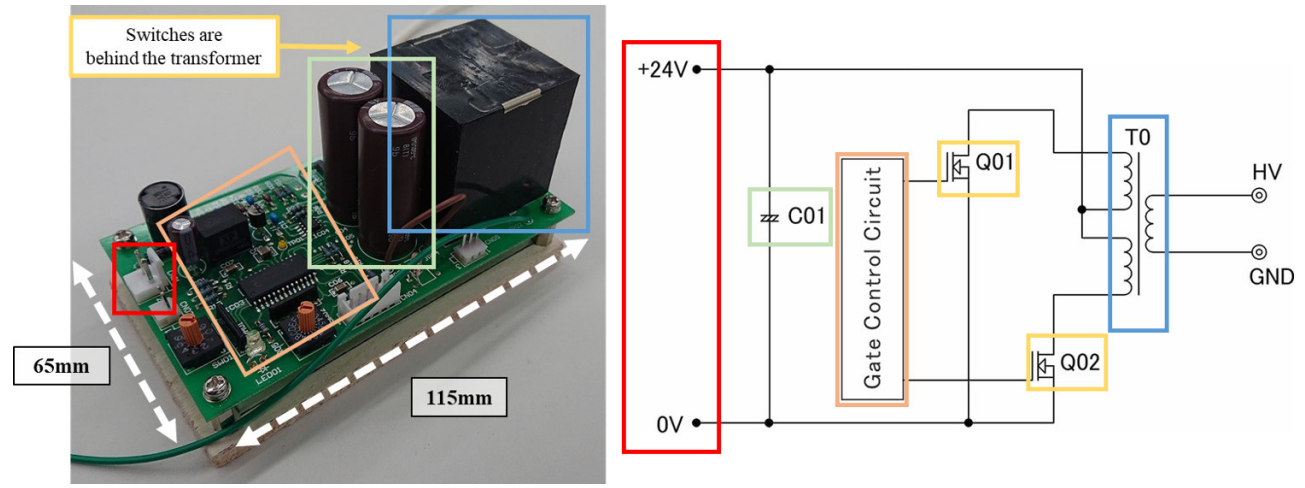

Figure 4. Small HV power supply used for flight test.

Table 2. Specifications of small HV power supply.

\begin{tabular}{ll}
\hline Weight & $225 \mathrm{~g}$ \\
\hline Dimension & D115 $\mathrm{mm} \times \mathrm{W} 65 \mathrm{~mm} \times \mathrm{H} 60 \mathrm{~mm}$ \\
\hline Supply Voltage & DC $24 \mathrm{~V}$ \\
\hline Voltage amplitude & Approx. 7 to $8 \mathrm{kV}_{\mathrm{pp}}$ (fixed, depending on PA length) \\
\hline Base frequency $\left(f_{\text {base }}\right)$ & $6000 \mathrm{~Hz}($ fixed $)$ \\
\hline Burst frequency $\left(f^{+}\right)$ & 100 to $600 \mathrm{~Hz}($ every $100 \mathrm{~Hz})$ \\
\hline Burst ratio $(B R)$ & 0 to $100 \%$ (every $10 \%)$ \\
\hline Design load & $280 \mathrm{pF}$ (under no-load condition) \\
\hline
\end{tabular}

Three approaches can be considered to miniaturize this power supply. In the first approach, an LC-series-transient-resonance circuit is applied. This circuit enables doubling the output voltage without enlarging the transformer. The second approach involves predetermining the shape of the target DBD-PA. Although the capacitance increases because of the presence of a surface charge, the increase in capacitance in the present DBD-PA is considered to be small. Based on this consideration, the capacitance of the transformer and inverter and the FET element were selected according to the estimated current parameters (peak value, effective value, frequency, etc.). 
Although the resonance period $T$ of the LC-series-transient-resonance circuit increases according to the increase in the capacitance during discharge, the power supply was designed while confirming that $T$ was within the half-wave period of the target drive frequency. This estimation enables selecting the minimum necessary elements. The third approach is to limit the modifiable parameters of the output waveform. To develop this power supply, we set the burst frequency and $B R$ as variable and the voltage, amplitude, and frequency of the voltage to be fixed. These approaches enable an HV power supply that is sufficiently small to be installed on the UAV.

Figure 5 displays a comparison of output waveforms from power supplies toward a 1-m-length DBD-PA. The output waveforms from the small HV power supply are illustrated in blue (with $0.2 \mathrm{~m}$ wire) and black (with $1.0 \mathrm{~m}$ wire) lines. For comparison, the output waveforms from an amplifier (Model 10/40A, Trek), which is typically used for driving a DBD-PA in wind tunnel experiments, are displayed in green $\left(V_{p p}=8 \mathrm{kV}\right)$ and red $\left(V_{p p}=9 \mathrm{kV}\right)$ lines. Although the output waveform from the small HV power supply is the corrupted sinusoidal wave, this power supply can provide approximately $8 \mathrm{kV}$ peak-to-peak waveforms.

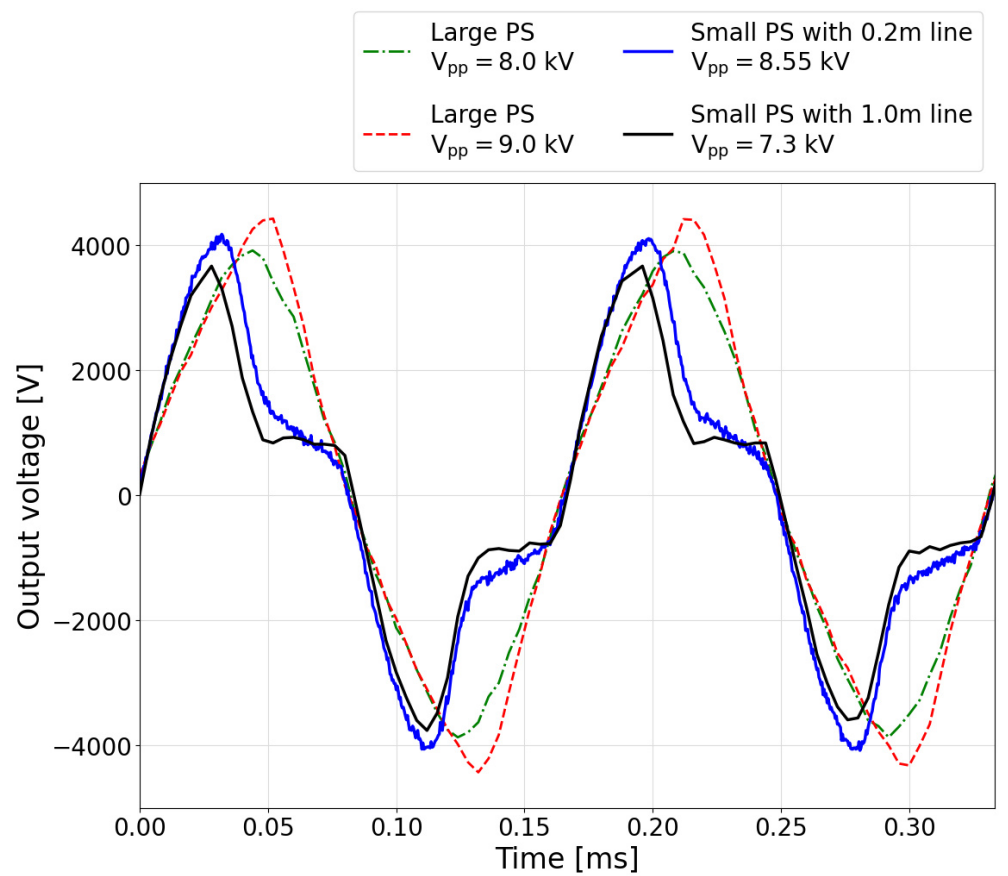

Figure 5. Output waveform from the small HV power supply when a $1 \mathrm{~m}$ length DBD-PA was connected. Notably, this small HV power supply cannot configure the output voltage amplitude, and the waveform depends on the circuit impedance.

The length of the wire between the PA and the power supply changes the circuit impedance, which results in the difference in the output waveform. Preliminary PIV experiments in a wind tunnel have revealed that the output waveform of $7.3 \mathrm{kV}$ peak-peak voltage can induce a velocity of approximately $1.5 \mathrm{~m} / \mathrm{s}$ at $2.5 \mathrm{~mm}$ downstream from the DBD-PA. This induced velocity is sufficiently robust to control the flow around the UAV with the stall speed. For more details, see reference [36]. 
Here, power measurement was conducted with a $0.2 \mathrm{~m}$ wire. The total power (active + reactive) was evaluated using the VQ Lissajous method with reference to Ashpis's work [37]. The total power of one AC cycle period is equal to the area inside the closed Lissajous curve in the Q-V plane. A $68 \mathrm{nF}$ capacitor was used as the monitor capacitor. Figure 6 displays the VQ Lissajous curve for this power measurement. The waveforms for the 30 cycles were superimposed. The result revealed that a total power of approximately $4.7 \mathrm{~W}$ was supplied to the 1-m length DBD-PA by a small power supply.

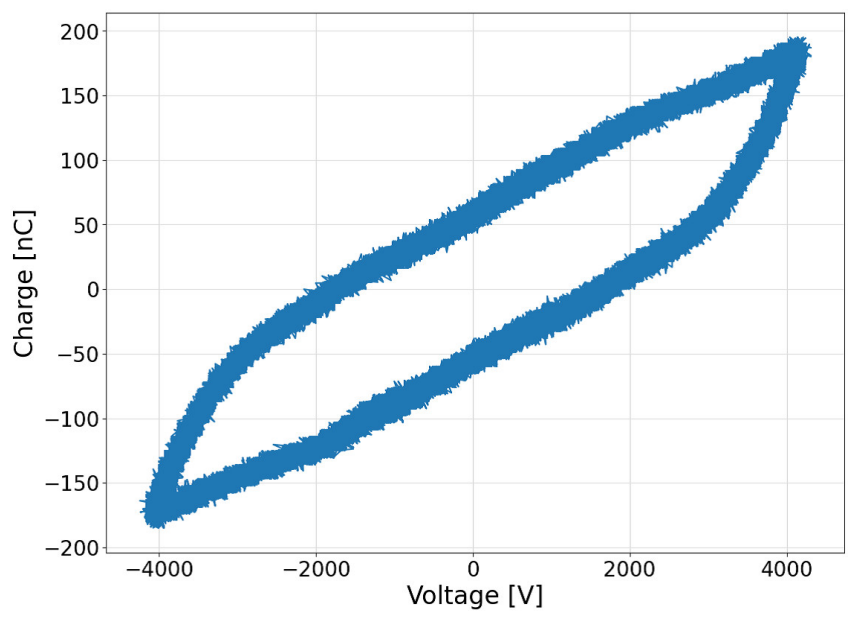

Figure 6. VQ Lissajous curve for the measurement of supplied power from the small power supply to $1 \mathrm{~m}$ DBDPA with an approximately $0.2 \mathrm{~m}$ wire.

This small power supply was driven by a $24-\mathrm{V}$ DC, and a three-cell lipo battery (Turnigy, 1000 mAh 3S 20C-30C) and a booster circuit (DROK, LM2577 DC) were used in this experiment. By connecting a pulse with modulation switch (Turnigy, receiver controlled switch) to this power supply, PA was driven by remote control from the RC transmitter.

A DBD-PA was installed at the leading edge of both the left and right main wings between $430 \mathrm{~mm}$ and $850 \mathrm{~mm}$ from the wing root. The discharge length of the DBD-PA on one wing was set to $400 \mathrm{~mm}$. PA consisted of two sheets of $70 \mu \mathrm{m}$ thick copper tape (3M, $\mathrm{Cu}-35 \mathrm{C}$ ) and two sheets of $80 \mu \mathrm{m}$ thick polyimide insulating layer (Teraoka Seisakusho, 650S, material thickness $50 \mu \mathrm{m}$ ). The widths of the exposed and insulated electrodes were 6 and $15 \mathrm{~mm}$, respectively.

These electrodes were placed at the leading edge so that the rear edge of the exposed electrode and the front edge of the insulated electrode were aligned without overlapping. DBD-PAs were driven in the burst mode with a $200-\mathrm{Hz}$ frequency and a $20 \%$ BR. Notably, this frequency was fixed for all experiments. As we focused on the stall delay, we selected the stall velocity as the freestream velocity for dimensionalization in Equation (1). From preliminary experiments, the stall velocity was approximately $6 \mathrm{~m} / \mathrm{s}$, and we confirmed that the $200 \mathrm{~Hz}$ burst frequency corresponded to a nondimensional frequency of approximately 6.7 .

Again, the characteristics of the smaller HV power supply used in this study were reported in Ref. [36]. Reference [38], for example, developed their own power supply and experimentally confirmed its effective control of a plasma actuator for airfoil flows at the lower freestream speed of $5 \mathrm{~m} / \mathrm{s}$.

\subsection{Autonomous Flight-Control System}

To evaluate the aerodynamic performance improvement by using a DBD-PA, each flight experiment should be conducted under the same conditions. Therefore, the autonomous flight control system was installed on the UAV, and Pixhawk was selected. Pixhawk is an independent open-hardware project that aims to provide the standard for readily available, high-quality, and low-cost autopilot hardware designs for academic, hobby, and developer communities [39]. 
An autonomous flight control system can be developed simply by connecting the control lines of a UAV to this module. The open-source flight control software PX4 [40] runs on Pixhawk. In this experiment, the open-source software was unmodified, and the "position mode", which is one of the control modes supported by PX4, was used. This mode autonomously maintains the altitude and flight direction, and enables an operator to control the airspeed (not thrust) with the throttle of the RC controller.

When the set airspeed was reduced by an operator, the autonomous flight system controlled the elevator to increase the pitch angle to maintain a constant lift force and altitude. If the set airspeed was set to a low value, the autonomous flight system would continue to increase the pitch angle, and eventually the UAV would reach a stall state. We used DBD-PAs to delay this stall, and aimed to display aerodynamic performance improvement. This method is similar to that adopted by Grundmann et al. [30].

\subsection{System Diagram}

The equipment configuration of the UAV employed in this experiment is displayed in Figure 7 . In the figure, the power line, input to the maneuver, and aircraft state information are represented by black, red, and blue lines, respectively. The connection by electric wire is represented by solid lines, whereas the communication between the ground station and UAV is represented by dotted lines. Two types of communication are typically used: communication to control the aircraft from the RC transmitter, and communication with the ground station PC to read the current aircraft information and rewrite the PX4 parameters. The second communication was performed using the software "QGroundControl".

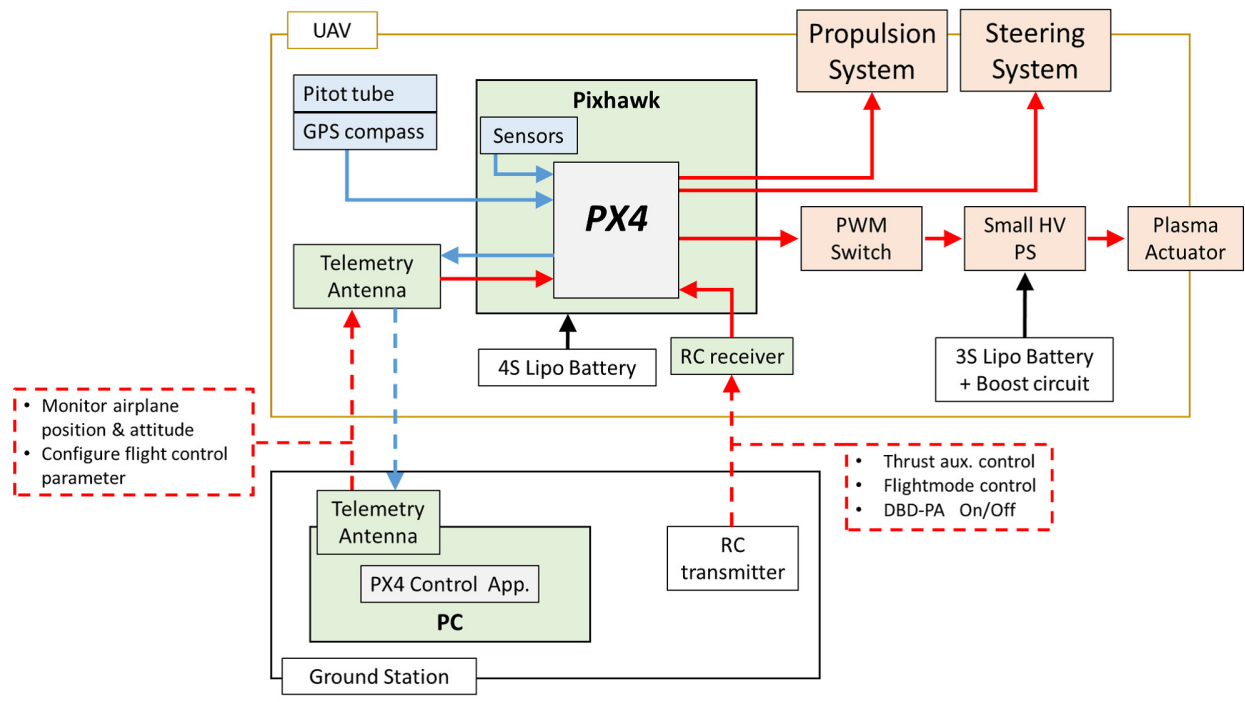

Figure 7. Overview of the UAV system, including the DBD-PA driving system and autonomous flight control system.

Here, the impact of the weight of the DBD-PA driving system on the overall weight is mentioned. The total weight of the UAV in the flight test was approximately $3200 \mathrm{~g}$. The DBD-PA driving system consisted of a small HV power supply, a three-cell lipo battery, a booster circuit, a pulse-width-modulation switch, high-voltage cables, and a DBD-PA. The small HV power supply weighed $225 \mathrm{~g}$ as illustrated in Table 2. A three-cell lipo battery, a booster circuit, a pulse-width-modulation switch, high-voltage cables, and a DBD-PA weighed $87 \mathrm{~g}, 10 \mathrm{~g}, 7 \mathrm{~g}, 16.3 \mathrm{~g}$, and $9.8 \mathrm{~g}$, respectively. Therefore, the total weight of the DBD-PA driving system was approximately $355 \mathrm{~g}$, which was approximately $11 \%$ of the total weight. Table 3 summarizes the impact of each item on the overall UAV weight. 
Table 3. Impact of items on the overall weight.

\begin{tabular}{|c|c|c|}
\hline Item & Weight $[\mathrm{g}]$ & Impact on Overall [\%] \\
\hline UAV & 1930 & 60.3 \\
\hline Propulsion battery & 420 & 13.1 \\
\hline PA system & 355 & 11.1 \\
\hline $\begin{array}{l}\text { Autonomous flight system } \\
\text { and related items }\end{array}$ & 495 & 15.5 \\
\hline Total & 3200 & \\
\hline
\end{tabular}

\section{Results of Flight Test}

The flight tests were conducted in the flight field for small UAVs along a river bed. Figure 8 displays an example of a flight test path at the flight field. The ground station was located in the center of the flight field, and the UAV flowed along the river and turned at the north and south ends. The section approximately $500 \mathrm{~m}$ in the center of the flight path in the north-south direction was used as the experimental section. To minimize the effects of wind, flights were conducted until approximately $4 \mathrm{~h}$ from sunrise. The flight timing was selected when the wind speed estimated with a windsock was within $2 \mathrm{~m} / \mathrm{s}$ The direction of the experimental section was determined such that the wind was a headwind. Flight tests were not conducted when the wind was blowing east-west.

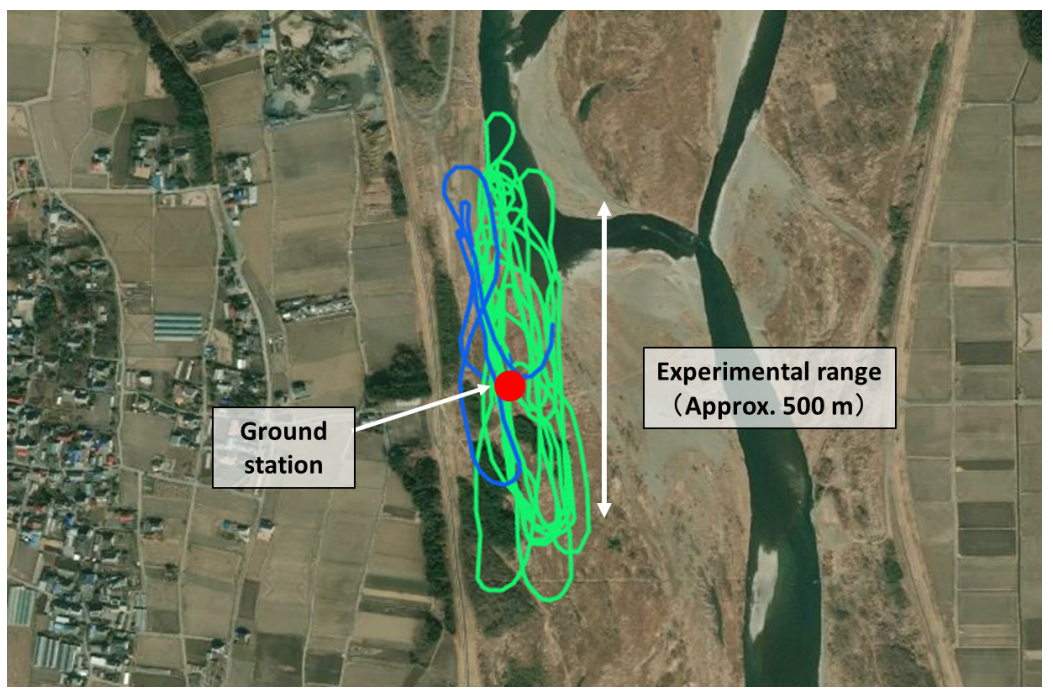

Figure 8. Flight test field and an example of a flight path. Figure is extracted from a flight log using the website of Flight review.

An example of the flight data is displayed in Figure 9. The green-filled areas represent sections in the position mode. The red-filled areas represent sections in which the DBD-PA is switched on. The red, blue, and black lines indicate the time-series data of the airspeed, pitch angle, and altitude, respectively. This figure reveals that the pitch angle increased as the airspeed decreased, whereas the altitude was almost constant at approximately $60 \mathrm{~m}$ in each experimental section. As flight tests were conducted outdoors, an unexpected external wind caused differences among flights. Therefore, 246 ON/OFF pairs of flights were conducted to obtain the statistical trends. 


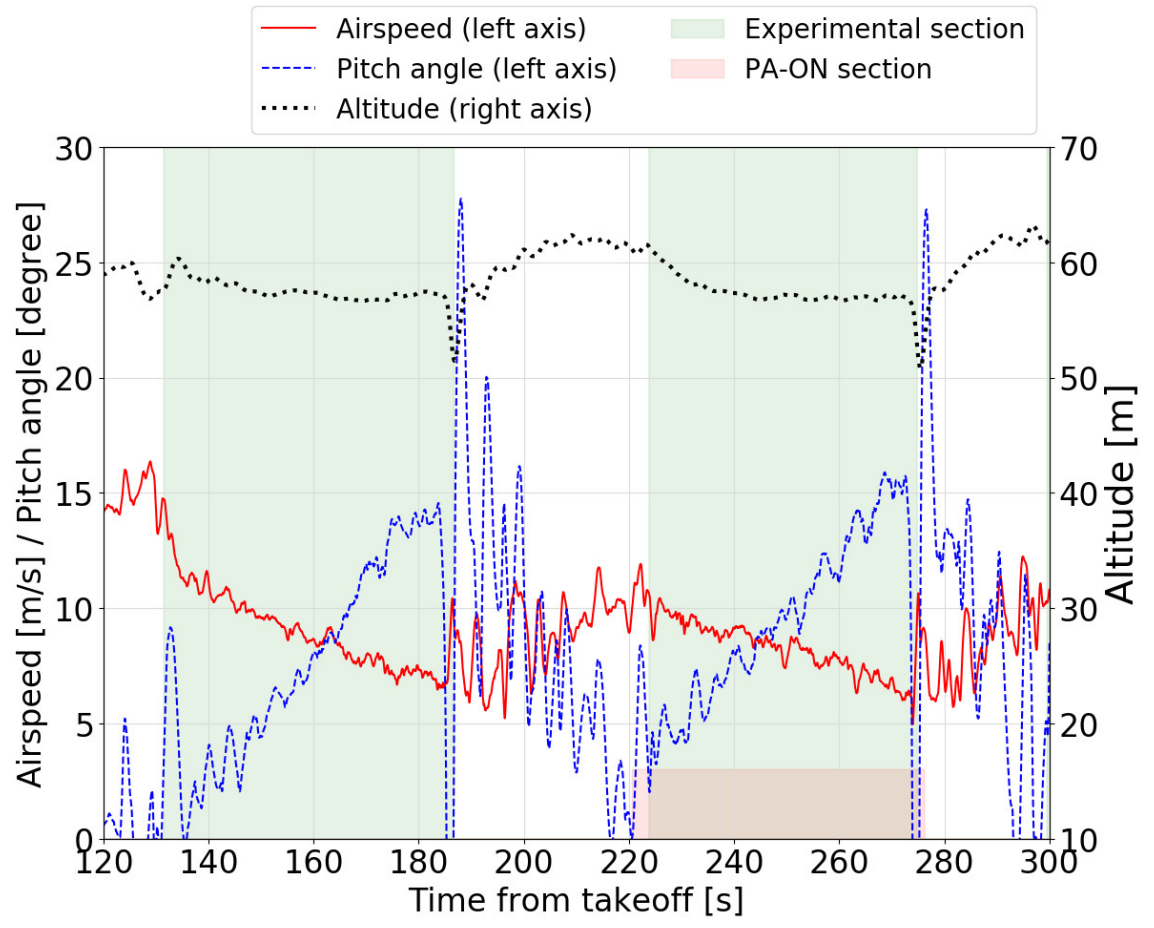

Figure 9. Example of time-series plots of flight data.

\section{Evaluation of DBD-PA Flow Control}

As the flight behavior did not necessarily change similarly every time because of the influence of external wind, it was difficult to obtain "average flight behavior" by ensembleaveraging the flight data. The direct relationship between the pitch angle and the airspeed is considered.

Figure 10 displays a 2D histogram plot between the pitch angle and airspeed using all 246 flight pairs. Time-series of the data in all the flights shown in Figure 9 was used in Figure 10. In this plot, pitch angles in the horizontal axis and airspeeds in vertical axis are divided into small portions with 0.1 increments. The airspeed and pitch angle data were recorded at each time instance of the measurement of each flight, and thus there are numbers of datasets of pitch angle and airspeed in each flight. A dot is plotted if the pitch angle and airspeed of one dataset falls into that portion. The number of frequencies is counted and summed up for each small portion of Figure 10.

The color of each dot changes based on the number of counts in that portion as the histogram bar in the right side of Figure 10 indicates In both plots, a high appearance frequency was distributed from the upper left to the lower right of the figure, which indicated that the pitch angle increased as the airspeed decreased. The width of the distribution represents the difference between flights because of the influence of external wind or the difference in the experimental initial state.

Comparing these figures, almost no difference was observed in the distribution near the figure center. However, the $\mathrm{ON}$ case exhibited a higher appearance frequency than the OFF case in the region where the pitch angle was 20 degrees or more, and the airspeed was $6 \mathrm{~m} / \mathrm{s}$ or less,which qualitatively indicated that a DBD-PA delayed the stall and achieved a higher pitch angle and a lower airspeed, as expected.

Next, flight data were postprocessed for quantitative comparisons. Grundmann et al. [30] established the method to extract the stall speed from time-series airspeed data, conducted a few tens of flight tests, and successfully evaluated the control effect of DBD-PA quantitatively. However, the flight data obtained from our flight tests fluctuated considerably, and detecting stalls with previous methods was difficult. Therefore, we focused on the attitude and control parameters during flight, and extracted the cruise condition from the flight data. The following three parameters were considered. 
- $\quad$ Pitch angular rate (Figure $11 \mathrm{a}, Q=\frac{d \theta}{d t}[\mathrm{deg} / \mathrm{s}]$, where $\theta$ is the pitch angle).

- $\quad$ Roll angle (Figure 11b, $\phi$ [deg]).

- Roll-control magnitude (Figure 11c, $\left.\mathrm{Control}_{\phi}[-]\right)$.

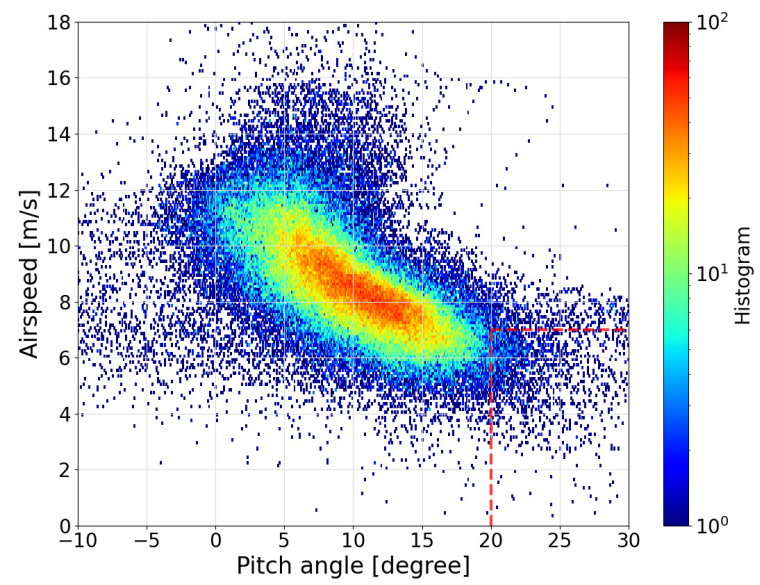

(a)

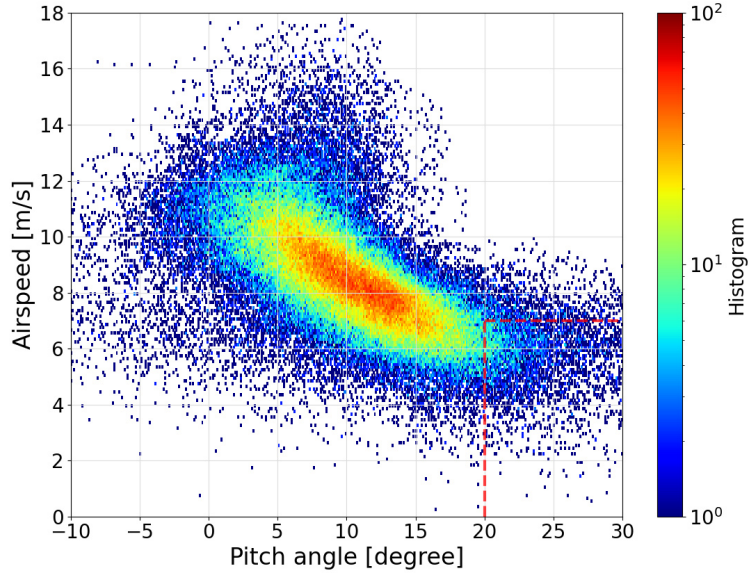

(b)

Figure 10. Histogram of flight log between the pitch angle and the airspeed. (a) DBD-PA OFF, (b) DBD-PA ON.

These parameters are almost zero for the cruise condition, whereas they fluctuated considerably when a stall occurred. Figure 11 display examples of time-series plots of these parameters. The red line represents the time-series data of each parameter, and the blue line represents that of the pitch angle for comparison. When the pitch angle abruptly decreased, that is, when a stall occurred, these three parameters also changed abruptly.

To extract stall timing, a threshold was set for each parameter, and the cruise condition was defined as the case in which the absolute values of all the parameters were less than each threshold range. In this study, we determined the thresholds based on the averages of the maximum values for all 246 flight datasets. Table 4 displays the averages of the maximum values. Here, the ratio of the threshold value to the averaged maximum value is set to $50 \%$. The effect of this ratio is discussed to evaluate the uncertainty of this method. 


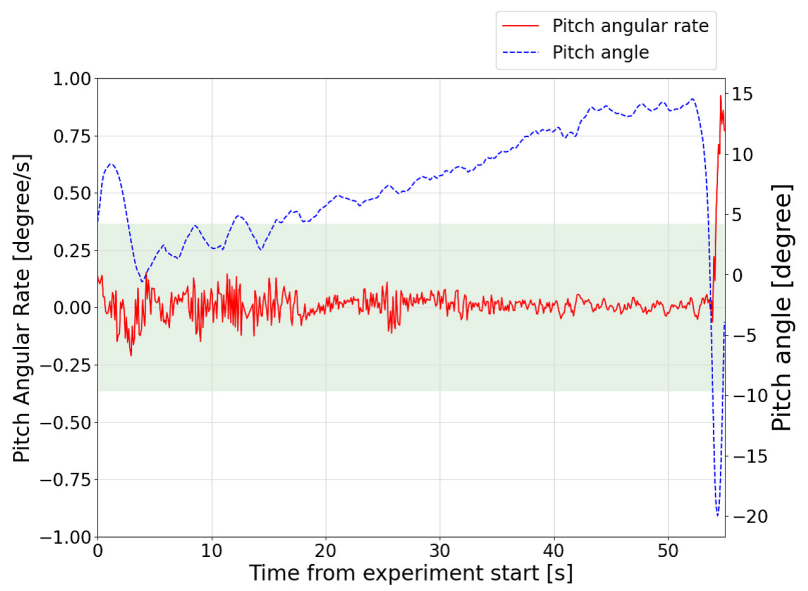

(a)

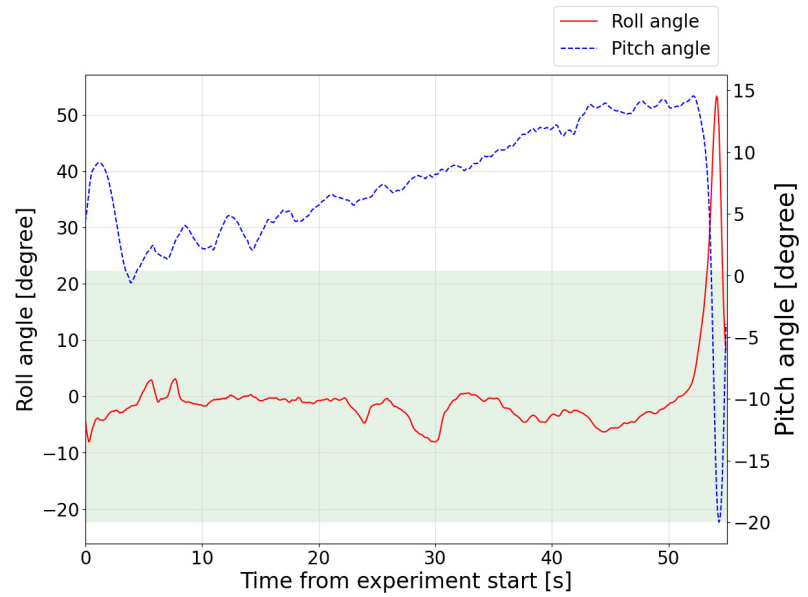

(b)

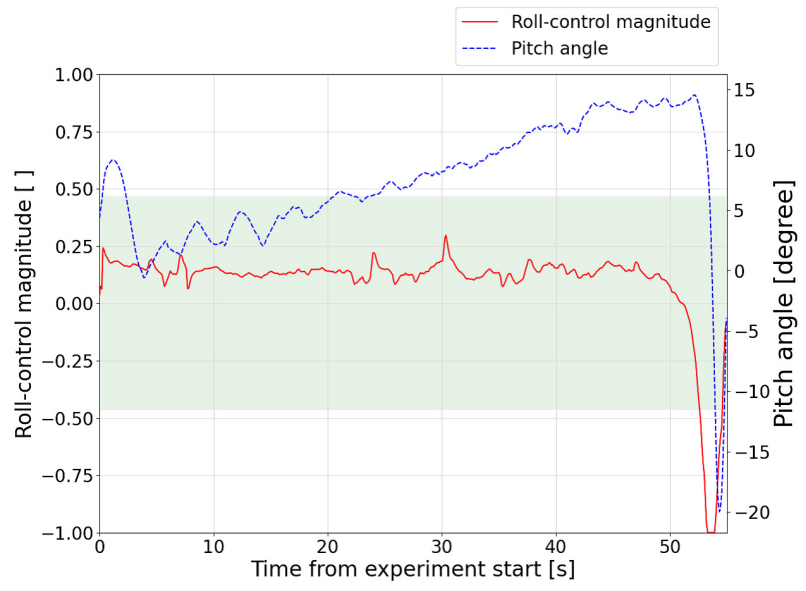

(c)

Figure 11. Time series plots of the pitch rate, the roll angle, and the roll-control magnitude. (a) Pitch angle rate, (b) Roll angle, (c) Roll-control magnitude. 
Table 4. Averages of the maximum values in all the 246 flight datasets for the thresholds.

\begin{tabular}{rrr}
\hline Parameter & Average & Standard Deviation \\
\hline$Q[\mathrm{deg} / \mathrm{s}]$ & 0.730 & 0.272 \\
\hline$\phi[\mathrm{deg}]$ & 44.6 & 17.8 \\
\hline Control $_{\phi}[-]$ & -0.932 & 0.185 \\
\hline
\end{tabular}

The green-filled region in Figure 11 indicates the definition range of the cruise condition. First, the cruise state data were extracted for each flight data according to the aforementioned rules. Next, the maximum pitch angle was extracted from each cruise state data. Figure 12 and Table 5 illustrate the results of the extraction. Each point plotted in Figure 12 corresponds to one pair of the ON/OFF flight data. The maximum pitch angle for PA-OFF is plotted in the $\mathrm{X}$ coordinate and that for PA-ON is plotted in the $\mathrm{Y}$ coordinate, respectively.

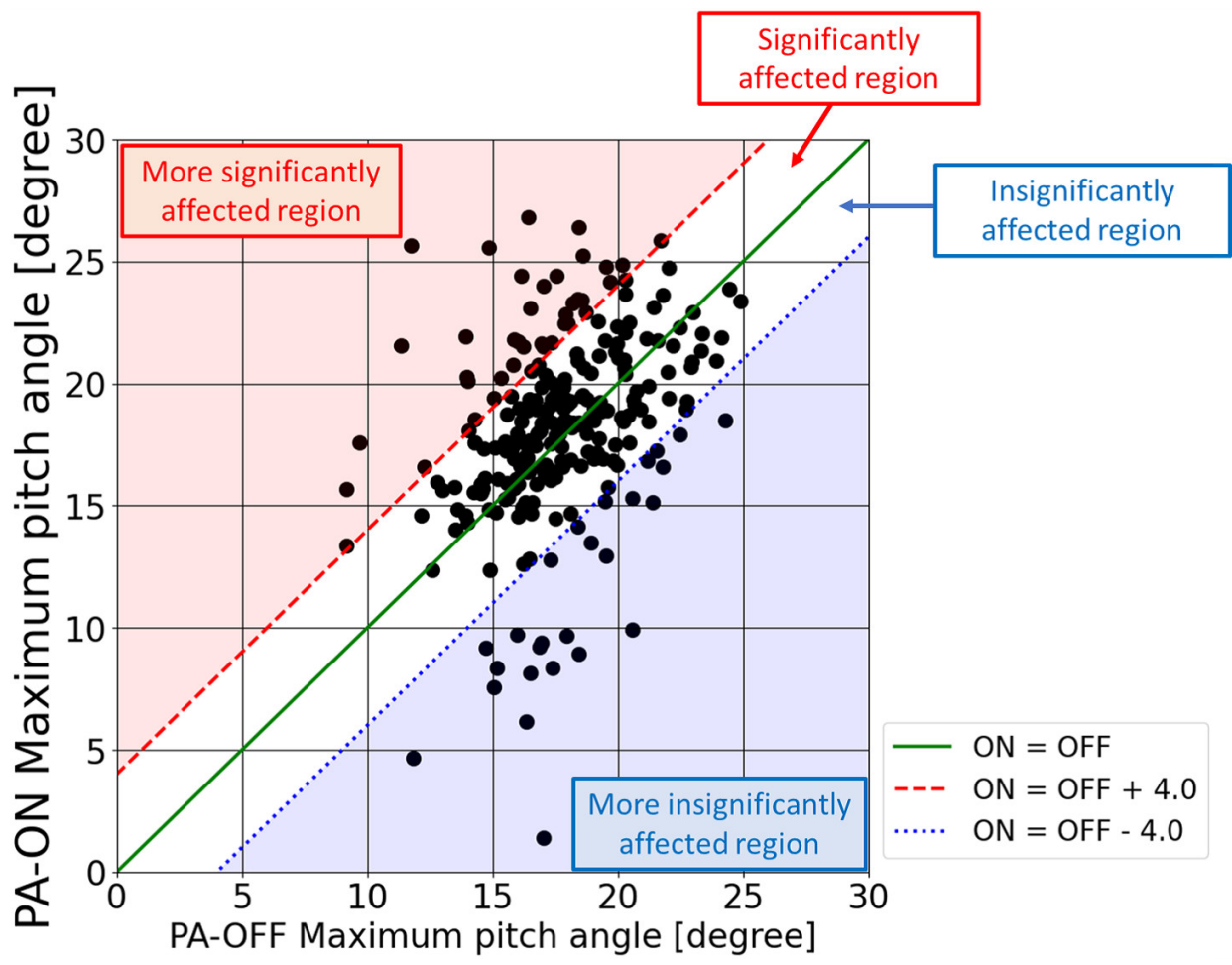

Figure 12. Comparison of the effect when DBD-PA is switched ON and OFF on the maximum vehicle pitch angle.

Table 5. Evaluation of DBD-PA control.

\begin{tabular}{lc}
\hline Number & Vehicle Pitch Angle \\
\hline Total Case Num & $\mathbf{2 4 6}$ \\
\hline ON $>$ OFF (better) & $146(59.3 \%)$ \\
\hline ON $<$ OFF (worse) & $100(40.7 \%)$ \\
\hline ON $>$ OFF +4 (much better) $[\mathrm{deg}]$ & $39(15.9 \%)$ \\
\hline ON $<$ OFF -4 (much worse) $[\mathrm{deg}]$ & $26(10.6 \%)$ \\
\hline
\end{tabular}

If the maximum pitch angles did not change even when PA becomes $\mathrm{ON}$, the point of the flight data would appear on the green line represented as "ON $=\mathrm{OFF}^{\prime}$ in the plot. When flow control effect of PA is clearly observed, data points would be located above 
the green line. They are marked "significantly affected" in the figure. Points would be located further up in the region colored in red when the effect of the plasma actuator is strongly recognized.

They are marked "more significantly affected" in the figure. Similarly, when flow control effect of PA is not clearly observed, the points would be located below the green line. They are marked "insignificantly affected". Sometimes, they are in the region colored in blue. They are marked "more insignificantly affected".

If a DBD-PA exhibited no flow-control authority, data points would be distributed randomly above and below $50 \%$ in Figure 12 simply by the environmental effects. Then, the percentage of data points in the "significantly affected" region would be come statistically approximately $50 \%$.

The figure reveals that most of the data points were distributed around the green line, indicating that the flow control capability of a DBD-PA was insufficient to bias the distribution. Table 5 indicates that the number of data points in the significantly affected region was approximately 1.5 -times larger than that of the insignificantly affected region. If DBD-PA had no effect on the flight and only environmental effects existed, the probability that $60 \%$ or more of the 246 flight data will be distributed in the "significantly affected" region can be calculated as follows. Therefore, the results presented in this study shows flow control authority of DBD-PA.

$$
\frac{\sum_{k=147(=246 \times 0.598)}^{246}{ }_{246} C_{k}}{\sum_{k=0}^{246}{ }_{246} C_{k}}=0.003=0.3 \%
$$

Next, we focus on the region of "significantly/insignificantly affected". In Figure 12, the red line indicates that the maximum pitch angle of PA-ON is 4.0 degrees larger than that of PA-OFF. It is denoted as "ON = OFF + 4.0 [deg]" in the caption. Similarly, the blue line indicates that the maximum pitch angle of PA-ON is 4.0 degrees smaller than that of PA-OFF. It is denoted as "ON $=\mathrm{OFF}-4.0$ [deg]" in the caption.

Again, the region colored in red above the red line is called the "more significantly affected" region, and the region colored in blue below the blue line is called the "more insignificantly affected" region. As listed in Table 5, the number in the "more significantly affected" region is still 1.5-times larger than that in the "more insignificantly affected" region. This difference would not occur if a DBD-PA had no flow control authority; therefore, this difference indicates the control capability of a DBD-PA.

Again, the present analysis method determines the stall timing based on the threshold being set independently for three parameters, pitch angular rate, roll angle, and roll-control magnitude. The threshold value for each parameter was determined based on the average of the maximum value for all the 246 flight datasets listed in Table 4 . The results shown in Figure 12 and Table 5 were obtained when the ratio of the threshold value to the averaged maximum value was set to $50 \%$. As the result depends on the ratio chosen, the effect of the ratio choice is investigated in the following section.

Figure 13 shows the ratio of flight data in each region represented in Figure 12 plotted with changing the ratio of the threshold value to the averaged maximum value from $5 \%$ to $95 \%$. As these three parameters oscillated slightly around zero even before a stall, the cruise condition was not extracted correctly when the ratio (thresholds) was too small. However, the ratio of each region was almost constant over a wide range of the ratio of the threshold value, including $50 \%$. The plot reveals that the results displayed in Figure 12 and Table 5 were robust rather than variable at certain thresholds, demonstrating the PA control effect on the UAV in this study. 


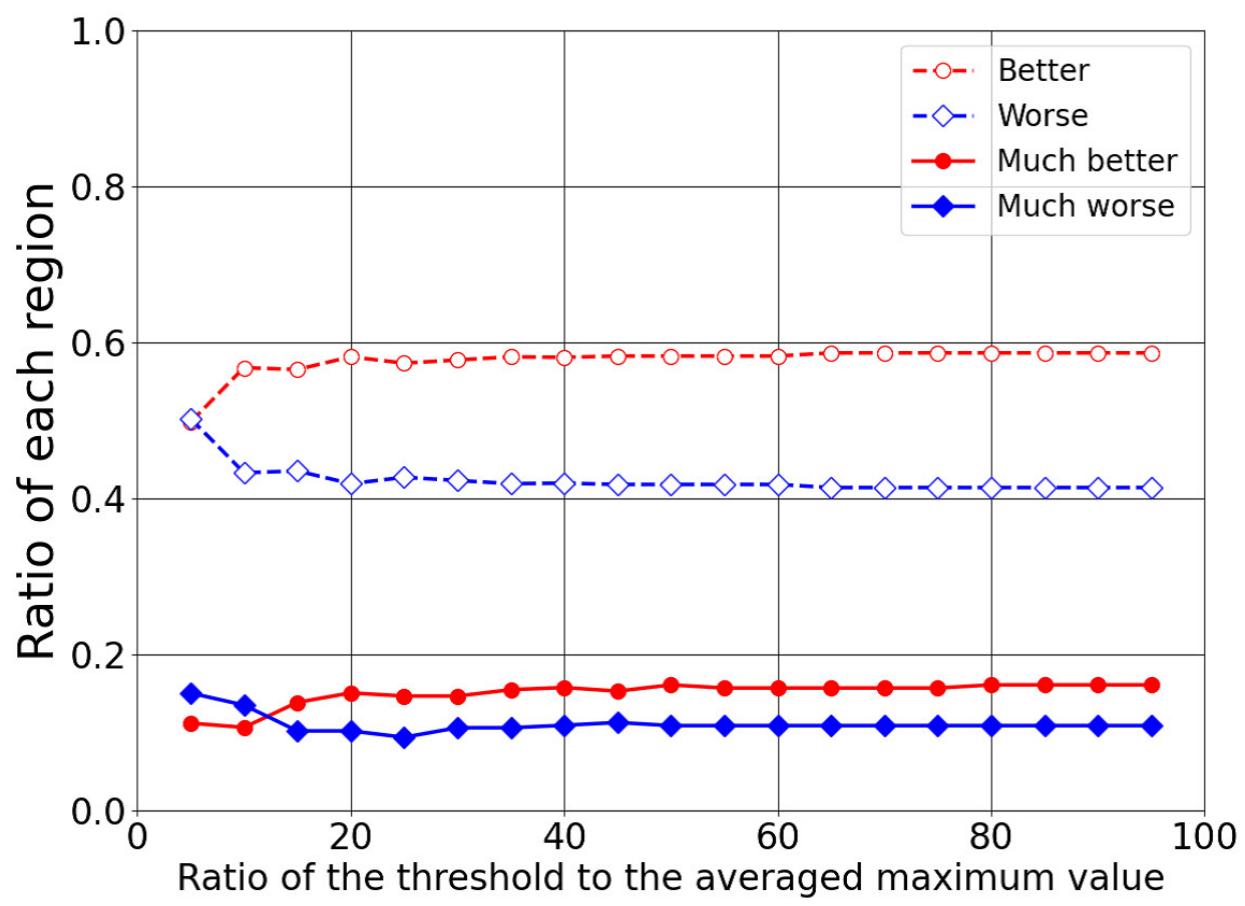

Figure 13. Impact of the ratio of the thresholds to the averaged maximum values in Table 4 on the the results.

Under ideal environmental conditions, the data plots in the "insignificantly affected" and "more insignificantly affected" regions in Figure 12 would not appear. Here, we discuss possible sources of such variation of the data and propose a way to reduce such variation, resulting in more convincing data. The main reason would be environmental conditions, such as the natural wind effect. Measurement of the instantaneous wind at the flight height would be useful for more precise analysis. This would enable calculating the exact instantaneous angle of attack and classifying the flight test into either "under weak wind conditions" or "under strong wind conditions".

Testing in steadier conditions would be desirable. Considering the DBD-PA and UAV set up, finding a more effective electrode layout (i.e., appropriate electrode span length and its location), and using the stronger DBD-PA system are both important for obtaining more convincing results. Flow visualization with a CCD camera using tufts over the wing surface [41] may be helpful for specifying PA-ON flights. It should be noted that some of these may increase the weight of the UAV. There may be slight possibilities that the "apparent negative effect" is a real negative effect physically.

Reference [42] indicated that L/D (lift by drag ratio) stayed high but lift itself became low for PA-ON when angles of attack became slightly lower than the stall angle. In the flight test, only pitch angles were measured (under controlled altitude), and instantaneous angles of attack were not measured. With the change of external wind conditions, this physical phenomenon might affect the results in Figure 12; however, measurement of angles of attack and tuft flow visualization would exclude such cases. Continuous future studies would further identify the effectiveness of DBD-PA for aircraft stall control in the real flight of UAVs.

\section{Conclusions}

An initial examination regarding stall improvement of a UAV with DBD-PA was conducted in this study. A novel HV power supply, which is small and sufficiently light to be mounted on a commercially-available UAV, was used, and a DBD-PA drive and autonomous flight systems were mounted on the UAV.

The autonomous flight system gradually pitched up the UAV and caused the stall from the cruise condition, and the DBD-PA delayed the stall. A total of 246 preliminary 
flight tests with the UAV were performed. A histogram using all flight data qualitatively indicated that flights with a DBD-PA could obtained a higher pitch angle and a lower airspeed. In addition, the cruise condition was defined using three parameters, and the maximum pitch angles of PA-ON and PA-OFF were extracted for each flight. This extraction quantitatively indicated the stall improvement by a DBD-PA.

In previous studies, the flow control capability of a DBD-PA was investigated under ideal conditions, such as wind tunnels and computational environments. However, few studies have been conducted on UAV flight testing using DBD-PAs because of restrictions for mounting regarding size and weight. Although this is an early stage of our research project, this study successfully revealed the flow control capability of a DBD-PA. Furthermore, because this study used a commercially available UAV and autonomous flight control system rather than self-made UAVs, the effects of DBD-PA can be obtained without special aircraft specifications, and readers can easily try the similar experiments described in this study.

Author Contributions: Conceptualization, H.K., S.S. and K.F.; methodology, H.K. and H.Y.; validation, K.F. and H.Y.; formal analysis, S.S.; investigation, S.S.; data curation, S.S. and H.K.; writingoriginal draft preparation, S.S.; writing — review and editing, S.S. and K.F.; visualization, S.S.; supervision, K.F. and H.Y.; project administration, K.F.; funding acquisition, K.F. All authors have read and agreed to the published version of the manuscript.

Funding: This research was funded by by the Japan Society for the Promotion of Science (JSPS) through Grants-in-Aid for Scientific Research (KAKENHI) grant number JP18H03816.

Institutional Review Board Statement: Not applicable.

Informed Consent Statement: Not applicable.

Data Availability Statement: Not applicable.

Acknowledgments: The authors would like to thank K. Tajiri for great technical assistance with the experiments.

Conflicts of Interest: The authors declare no conflict of interest.

\section{References}

1. Enloe, C.L.; McLaughlin, T.E.; VanDyken, R.D.; Kachnew, K.D.; Jumper, E.J.; Corke, T.C. Mechanisms and Responses of a Single Dielectric Barrier Plasma Actuator: Plasma Morphology. AIAA J. 2004, 42, 589-594. [CrossRef]

2. Corke, T.C.; Enloe, C.L.; Wilkinson, S.P. Dielectric Barrier Discharge Plasma Actuators for Flow Control. Annu. Rev. Fluid Mech. 2010, 42, 505-529. [CrossRef]

3. Boeuf, J.P.; Lagmich, Y.; Unfer, T.; Callegari, T.; Pitchford, L. Electrohydrodynamic force in dielectric barrier discharge plasma actuators. J. Phys. D 2007, 40, 652-662. [CrossRef]

4. Nishida, H.; Abe, T. Numerical analysis of plasma evolution on dielectric barrier discharge plasma actuator. J. Appl. Phys. 2011, 110, 013302. [CrossRef]

5. Kotsonis, M.; Ghaemi, S.; Veldhuis, L.; Scarano, F. Measurement of the body force field of plasma actuators. J. Phys. D Appl. Phys. 2011, 44, 045204. [CrossRef]

6. Geuns, R.; Goekce, S.; Plyushchev, G.; Leyland, P.; Pimentel, R.; de Champlain, A.; Jean, Y. Understanding SDBD Actuators: An Experimental Study on Plasma Characteristics. In Proceedings of the AIAA Aviation, 45th AIAA Plasmadynamics and Lasers Conference, Atlanta, GA, USA, 16-20 June 2014; AIAA-2014-2811.

7. Benard, N.; Moreau, E. Electrical and mechanical characteristics of surface AC dielectric barrier discharge plasma actuators applied to airflow control. Exp. Fluids 2014, 55, 1846. [CrossRef]

8. Post, M.L.; Corke, T.C. Separation Control on High Angle of Attack Airfoil Using Plasma Actuators. AIAA J. 2004, 42, $2177-2184$. [CrossRef]

9. Visbal, M.R.; Gaitonde, D.V.; Roy, S. Control of Transitional and Turbulent Flows Using Plasma-Based Actuators. In Proceedings of the 36th AIAA Fluid Dynamics Conference and Exhibit, San Francisco, CA, USA, 5-8 June 2006; AIAA-2006-3230.

10. Greenblatt, D.; Goksel, B.; Schule, C.Y.; Romann, D.; Paschereit, C.O. Dielectric Barrier Discharge Flow Control at Very Low Flight Reynolds Numbers. AIAA J. 2008, 46, 1528-1541. [CrossRef]

11. Sato, M.; Aono, H.; Yakeno, A.; Nonomura, T.; Fujii, K.; Okada, K.; Asada, K. Multifactorial Effects of Operating Conditions of Dielectric-Barrier-Discharge Plasma Actuator on Laminar-Separated-Flow Control. AIAA J. 2015, 53, 2544-2559. [CrossRef]

12. Sekimoto, S.; Nonomura, T.; Fujii, K. Frequency Effects in Burst-mode Actuation of Dielectric-Barrier-Discharge Plasma Actuator for Separation Control. AIAA J. 2016, 55, 1385-1392. [CrossRef] 
13. Jukes, T.N.; Segawa, T.; Furutani, H. Flow Control on a NACA 4418 Using Dielectric-Barrier-Discharge Vortex Generators. AIAA J. 2013, 51, 452-465. [CrossRef]

14. Matsuno, T.; Kawaguchi, M.; Fujita, N.; Yamada, G.; Kawazoe, H. Jet Vectoring and Enhancement of Flow Control Performance of Trielectrode Plasma Actuator Utilizing Sliding Discharge. In Proceedings of the 6th AIAA Flow Control Conference, New Orleans, LA, USA, 25-28 June 2012; AIAA-2012-3238.

15. Corke, T.C.; Post, M.L. Overview of Plasma Flow Control: Concepts, Optimization, and Applications. In Proceedings of the 43rd AIAA Aerospace Sciences Meeting and Exhibit(USA), Reno, NV, USA, 10-13 January 2005; AIAA-2005-563.

16. Asada, K.; Ninomiya, Y.; Oyama, A.; Fujii, K. Airfoil Flow Experiment on the Duty Cycle of DBD Plasma Actuator. In Proceedings of the 47th AIAA Aerospace Sciences Meeting Including the New Horizons Forum and Aerospace Exposition(USA), Orlando, FL, USA, 5-8 January 2009; AIAA-2009-531.

17. Goksel, B.; Greenblatt, D.; Rechenberg, I.; Nayeri, C.N.; Paschereit, C.O. Steady and Unsteady Plasma Wall Jets for Separation and Circulation Control. In Proceedings of the 3rd AIAA Flow Control Conference(USA), San Francisco, CA, USA, 5-8 June 2006; AIAA-2006-3686.

18. Sidorenko, A.A.; Zanin, B.Y.; Postnikov, B.V.; Budovsky, A.D.; Starikovskii, A.Y.; Roupassov, D.V.; Zavialov, I.N.; Malmuth, N.D.; Smereczniak, P.; Silkey, J.S. Pulsed Discharge Actuators for Rectangular Wings Separation Control. In Proceedings of the 45th AIAA Aerospace Sciences Meeting and Exhibit, Reno, NV, USA, 8-11 January 2007; AIAA-2007-941.

19. Fujii, K. High-performance computing-based exploration of flow control with micro devices. Phlosop. Trans. R. Soc. A 2014, 372, 20130326. [CrossRef] [PubMed]

20. Skourides, C.; Nyfantis, D.; Leyland, P.; Bosse, H.; Ott, P. Mechanisms of Control Authority by Nanosecond Pulsed Dielectric Barrier Discharge Actuators on Flow Separation. Appl. Sci. 2019, 9, 2989. [CrossRef]

21. Little, J.; Takashima, K.; Nishihara, M.; Adamovich, I.; Samimy, M. Separation Control with Nanosecond-Pulse-Driven Dielectric Barrier Discharge Plasma Actuators. AIAA J. 2012, 50, 350-365. [CrossRef]

22. Fujii, K. Three flow features behind the flow control authority of DBD plasma actuator: Result of high-fidelity simulations and the related experiments. Appl. Sci. 2018, 8, 546. [CrossRef]

23. Borghi, C.A.; Cristofolini, A.; Neretti, G.; Seri, P.; Rossetti, A.; Talamelli, A. Duty cycle and directional jet effects of a plasma actuator on the flow control around a NACA0015 airfoil. Meccanica 2017, 52, 3661-3674. [CrossRef]

24. Zoppini, G.; Belan, M.; Zanotti, A.; Di Vinci, L.; Campanardi, G. Stall control by plasma actuators: Characterization along the airfoil span. Energies 2020, 13, 1374. [CrossRef]

25. Sekimoto, S.; Fujita, K.; Fujii, K. Flow-control experiment around half-span wing model for dbd-pa application on UAV. In Proceedings of the AIAA Scitech 2021 Forum, Virtual Event, Nashville, TN, USA, 11-15 \& 19-21 January 2021; AIAA-2021-1944.

26. Imanberdiyev, N.; Fu, C.; Kayacan, E.; Chen, I.M. Autonomous navigation of UAV by using real-time model-based reinforcement learning. In Proceedings of the 2016 14th International Conference on Control, Automation, Robotics and Vision (ICARCV), Phuket, Thailand, 13-15 November 2016; pp. 1-6.

27. Cui, J.h.; Wei, R.x.; Liu, Z.c.; Zhou, K. UAV motion strategies in uncertain dynamic environments: A path planning method based on Q-learning strategy. Appl. Sci. 2018, 8, 2169. [CrossRef]

28. Matsuda, H.; Tanaka, M.; Osako, T.; Yamazaki, K.; Simura, N.; Asayama, M.; Oryu, Y. Plasma Actuation Effect on a MW class Wind Turbine. Int. J. Gas Turbine Propuls. Power Syst. 2017, 9, 47-52. [CrossRef]

29. Sidorenko, A.A.; Budovsky, A.D.; Pushkarev, A.V.; Maslov, A.A. Flight Testing of DBD Plasma Separation Control System. In Proceedings of the 46th AIAA Aerospace Sciences Meeting and Exhibit, Reno, NV, USA, 7-10 January 2008; AIAA-2008-373.

30. Grundmann, S.; Frey, M.; Tropea, C. Unmanned Aerial Vehicle (UAV) with Plasma Actuators for Separation Control. In Proceedings of the 47th AIAA Aerospace Sciences Meeting Including the New Horizons Forum and Aerospace Exposition, Orlando, FL, USA, 5-8 January 2009; AIAA-2009-698.

31. Friedrichs, W. Unmanned Aerial Vehicle for Flow Control Experiments with Dielectric Barrier Discharge Plasma Actuators. Ph.D. Thesis, Technischen Universität Darmstadt, Darmstadt, Germany, 2014.

32. GBSElectronik. Special Pulse Generators. Available online: https://www.gbs-elektronik.de/en/hv-pulse-technology/specialpulse-generators.php (accessed on 20 December 2021).

33. Sekimoto, S.; Fujii, K.; Yoneda, H. Flow Control on an Unmanned Aerial Vehicle Using a Plasma Actuator Driven By a SubstrateSize Power Supply. In Proceedings of the AIAA Scitech 2020 Forum, Orlando, FL, USA, 6-10 January 2020; AIAA-2020-0825.

34. VOLANTEXRC. Volantex RC Ranger EX Long Range FPV/UAV Platform Unibody Big Weight Carrier (V757-3) PNP I VolantexRC. Available online: https:/ / www.volantexrc.eu/volantex-rc-ranger-ex-long-range-fpv-uav-platform-unibody-big-weight-carrierv757-3-pnp-p-224.html (accessed on 20 December 2021).

35. Hamada, S.; Moreno, C.P. Development of an Unmanned Aerial Vehicle (UAV) Research Platform for Flutter Analysis. In Proceedings of the 2018 AIAA Atmospheric Flight Mechanics Conference, Kissimmee, FL, USA, 8-12 January 2018; AIAA-2018-0021.

36. Sekimoto, S.; Fujii, K.; Hosokawa, S.; Akamatsu, H. Flow-control capability of electronic-substrate-sized power supply for a plasma actuator. Sens. Actuators A Phys. 2020, 306, 111951. [CrossRef]

37. Ashpis, D.; Laun, M.; Griebeler, E. Progress toward accurate measurements of power consumption of DBD plasma actuators. In Proceedings of the 50th AIAA Aerospace Sciences Meeting Including the New Horizons Forum and Aerospace Exposition, Nashville, TN, USA, 9-12 January 2012; AIAA 2012-823. 
38. Suzuki, K.; Komuro, A.; Sato, S.; Sakurai, M.; Mitsuhashi, K.; Sekiya, N.; Watanabe, Y.; Kanagawa, K.; Ando, A. Development of small high-voltage AC power supply for a dielectric barrier discharge plasma actuator. Rev. Sci. Instrum. 2021, 92, 024707. [CrossRef] [PubMed]

39. pixhawk. The Open Standards for Drone Hardware. Available online: http://pixhawk.org/ (accessed on 20 December 2021).

40. PX4. PX4 Autopilot User Guide (Master). Available online: https://docs.px4.io/master/en/ (accessed on 20 December 2021).

41. Yoneda, H.; Goto, A.; Kato, H.; Sekimoto, S.; Fujii, K. Flight Test of UAV with DBD-Pa Flow Control. In Proceedings of the AIAA Scitech 2021 Forum, Virtual Event, Nashville, TN, USA, 11-15 \& 19-21 January 2021; AIAA-2021-1942.

42. Ogawa, T.; Asada, K.; Tatsukawa, T.; Fujii, K. Computational Analysis of the Control Authority of Plasma Actuators for Airfoil Flows at Low Angle of Attack. In Proceedings of the AIAA Scitech 2020 Forum, Orlando, FL, USA, 6-10 January 2020; AIAA-2020-0578. 